\title{
RESEARCH ON THE GOOD LANGUAGE TEACHER
}

RICARDo SAN MarTín Vadillo Aula de Extensión de Alcalá la Real

\section{RESUMEN}

El presente artículo es fruto de un trabajo de investigación sobre el concepto del «buen profesor de idiomas". La literatura sobre el tema es extensa y diversos autores han estudiado lo que se encierra bajo esa denominación y han recogido las que deben ser, en opinión de alumnos y profesores, las características del buen profesor de idiomas.

I think every teacher tries to do his/her work better every day. I know lots of teachers whose interest in their students drives them to a constant search for more motivating activities, more efficient teaching methods and better designed materials for their classes. They spend a lot of time, inside and outside their classes, thinking about how to help their pupils. This constant reflection can be seen everywhere: in the different workshops orginized to share ideas, in the number of teachers who are members of professional organizations (AITEC, GRETA, TESOL, etc.), in the number of magazines and journals dealing with TEFL/TESL, in the many Web sites designed and used by teachers. The majority of language teachers I have known live these commitments daily.

What I present in my article is a compilation of some of the literature dealing with that interest on the part of the teacher for improvement and how it 
can be accomplished. The books and journals mentioned refer both to EFL and to ESL teaching. The objective of this article is to present different pieces of advice which can be really useful for any teacher. It is up to you to pick those which you consider that are worth putting into practice.

Politzer and Weiss (1971) suggested the hypothesis that the efficiency of the individual teacher increases with the amount of his/her personal stake. The claim that the communicative process involves the entire person can also be found in the work of other authors, such as Penner (1992:45) who says:

One who teaches effectively, teaches not only his subject but himself. Personality is that part of the teacher's self which he/she projects into every classroom activity, thereby affecting and conditioning every learning situation.

Finocchiaro and Bonomo (1973) tell us about the crucial role of the teacher in class and present a list of 16 tasks which the good language teacher should be able to put into practice:

- Plan in advance the situations with which the meaning of the new language items will be made clear to the students.

- Provide meaningful use of the language in communication activities where language is generally used by native speakers.

- Keep previously taught materials alive through judicious reintroduction in subsequent classroom lessons.

- Use the students' native language sparingly in the classroom, but not hesitate to use it to clarify instructions or to ensure that essential information has been understood.

- Learn how to engage the students in full class, group, and individual recitation procedures as appropriate. He/she should become accustomed to preparing or utilizing existing instructional materials. He/she should supplement the basic text where necessary by preparing drills, dialogues, or reading selections. $\mathrm{He} /$ she should become skillful in preparing scripts for tapes, and in integrating laboratory practice and classroom activity.

- Determine when beginning-level students are ready for reading and writing activities. (S)he should plan reading lessons which will provide students with an aesthetic experience. (S)he should incorporate writing activities which will lead gradually to more creative, «free» student expression when possible. (S)he should provide students with cultural insights into the foreign country. 
- Make sure that students retain their sense of individual dignity and national pride.

- Select and use only the audio-vidual aids which will help the students acquire a particular language structure.

- Give frequent tests which will help gauge the achievement of students, diagnose individual learning problems; and judge the effectiveness of his teaching.

Prator (1976:5) deals with ten slogans which he considers to be good advice for those teachers in search of a method:

1. Teaching is more an art than a science.

2. No methodologist has the whole answer.

3. Try to avoid the pendulum syndrome.

4. Place a high value on practical experimentation without doctrinaire allegiance.

5. Look at various relevant disciplines for insights.

6. View objectives as an overriding consideration.

7. Regard all tested techniques as resources.

8. Attach as much importance to what your students say as to how they say it.

9. Let your greatest concern be the needs and motivation of your students.

10. Remember that what is new is not necessarily better.

The next article to consider is the one written by Finocchiaro (1976). In it the author splits the word «m-o-t-i-v-a-t-i-o-n» and uses the mnemonic to give some practical advice to language teachers:

M: Motivation, Methodology, Meaning, Mother tongue, Mastery: We have to look both for Integrative and Instrumental motivation. Our methodology must be flexible. The mother tongue should be used sparingly and judiciously in the classroom.

O: Objectives: The primary goal of language teaching is to help the learner use the target language in the multiple functions it serves in real life and to develop his/her communicative competence.

T: Technique: The good language teacher will engage students in practice leading not only to habit formation but also to the internalization of the rules that govern the formation and use of a language.

I: Involvement, Integration: It is a need of great importance to involve and integrate the students in all phases of the teaching process. 
V: Values: Our students should be helped to appreciate the universality of the human experience, the values of their own culture as well as other people's.

A: Attitudes, Activities, Achievement, Articulation: The teacher should plan activities which are satisfying and productive for his/her students.

$\mathrm{T}$ : Transfer, Translation, Textbooks, Testing: We should note that students, at the early stages of learning a foreign language, try to think of the equivalent of a term or a structure in their native tongue. As for textbooks we must say that the perfect one does not exist, so it is the teacher's job to add it to the characteristics of his/her students. Tests should be frequent, brief and previously announced.

I: Interference, Individualization: It is not quite clear whether the major cause of students' mistakes come from interlinguistic or intralinguistic interference. Individualization of instruction is desirable and necessary.

$O$ : Observation: The practice of teacher guided observation of other teachers is important.

$\mathrm{N}$ : Native culture, Needs: We can discuss the student's culture in the target language. Finally, $\mathrm{N}$ for Needs because the student needs to feel secure with respect to other teachers and peers.

The next article I would like to mention is the one by Robinett (1977). She starts by disagreeing with the statement «Teachers are born, not made» because she thinks teachers must acquire knowledge of a specific subject before they can teach it to others. As for the qualities of good teachers she mentions:

1. Inspiration: Effective teachers listen to students' problems and use inspiration to help them find solutions.

2. Enthusiasm: It comes from a genuine interest in the subject matter and from the satisfaction gained from watching students learn a second or foreign language.

3. Professional competence: It is a knowledge of the subject matter to be taught. It includes a linguistic awareness as what constitutes language; how language operates; how speech and writing are related; how languages compare and contrast; how language reflects the culture of its speakers, etc.

4. Consider the affective development of the students: It refers to the abilty to create a free and wholesome atmosphere in the classroom where students feel secure.

5. Tolerance, patience, warmth, sensibility and open-mindedness: All these are characteristics necessary in effective teachers

In summary, teachers must not only have a sound knowledge of the target language but a set of personal qualities: sensitivity, warmth and tolerance. 
Apelt (1981) wrote a direct and straightforward article. In it he described ten principles in foreign language teaching. Such principles were drawn from successful teaching practices in schools whose pupils were aged 10 to 18. Here is a summary of the fundamental issues and urgent problems in FLT:

1. Unity of language training and pupils' general education:

2. Complex development of language knowledge and language skills and abilities.

3. Communicative activity of all pupils.

4. Gradually increased language self-activity of the pupils.

5. Unity of cognitive and imitative language learning.

6. Unity of form and function in language acquisition.

7. Priority of the spoken language (speech)- without neglecting other relevant language skills.

8. Language learning in contexts- and not in isolated fragments.

9. Foreign language as medium of instruction in the classroomwithout excluding absolutely the use of the mother tongue.

10. Visualization in foreign language learning, especially by means of teaching aids.

The book written by Dulay, Burt and Krashen (1982:261) presents the application of research studies to teaching guidelines. In chapter 11 the credited authors present a series of classroom techniques. They provide us with some suggestions to improve the teaching of a second language: Maximize the student's exposure to natural communication; use concrete referents to make the new language understandable to beginning students; devise specific techniques to relax students and protect their egos, include some time for formal grammar lessons for adults; learn the motivation of your students and incorporate this knowledge into your lessons; create an atmosphere where students are not embarrassed by their errors; include current and socially useful phrases; do not expect students to learn «late structures» early; do not refer to a student's L1 when teaching the $\mathrm{L} 2$.

There are many professionals who insist that teaching is more an art than a science. This was argued by Çiftçi (1983). Based upon fifteen years' experience she presents some hints which can be useful for new (and experienced) teachers:

Love your students and have a passion for teaching; always address your students by name. This creates a friendly atmosphere; don't waste class time 
telling personal anecdotes that have nothing to do with what you should be teaching; be neat, tidy, and set a good example; don't let them dominate the class with their constant talking; don't grade a student's work when you are angry with him. Avoid creating tension: ask him questions and let him take part in the lesson, so that he will not think that his teacher is no longer interested in him; don't become too attached to the teacber's desk. Move around the room; praise your students when they do well; don't exaggerate your speech, speak as naturally as possible; mantain good eye contact with your students; let your students be aware of your trust in them; remember that a class consists of both good and bad students; learn your students' names; be good at discipline, but don't be too strict; break the tense atmosphere of the class by having a sense of humour; be punctual both in going to class and in leaving it as soon as the bell rings; don't react to the student who causes problems in class. Be as polite and as patient as possible. Create an atmosphere in which the students feel relaxed enough to express themselves; go from the known to the unknown, and from the regular to the irregular; don't forget that once you, too, were a student, put yourself in your students' place; check your students' homework regularly, especially at the beginning of the school year, let the students laugh when you draw stick figures. You laugh, too. The lesson will be more interesting; correct a student's mistake as soon as possible, but wait until he finishes the sentence, in order not to spoil the rhythm of the sentence; try to enable your students to speak English automatically and to think in English, even if their sentences contain mistakes; collect pictures of a large enough size to be seen at the back of the room; value every minute of the class period, and prepare interesting relaxation activities to use when there is time remaining at the end of the lesson; read about new developments in teaching the language, so tbat you won't use old-fashioned techniques; plan your lessons in advance; coordinate with other English teachers in your school for team teaching; don't depend entirely on the textbook; use previously learned grammatical patterns in teaching new vocabulary items, and previously learned vocabulary items in teaching new structures; never laugh or permit others to laugh at a student's mistake; from time to time let your students correct their own or a friend's work under your supervision; give frequent short quizzes on what has been taught, and return the corrected papers right away; give an oral exam before a written test, covering the same kind of material that the test will include.

Sanderson (1983) provides us with a list of 14 characteristics, with some subdivisions, of the good teacher of modern languages. The good language teacher:

- Uses the foreign language predomínantly.

- Is vigilant of the pronunciation, intonation and stress. 
- Praises correct responses; that good teacher is sympathetic/ positive about wrong responses.

- Conveys warmth in delivery of the message and through facial expression; a teacher who engages in intensive oral exploitation and material.

- Promotes understanding by non-verbal clues.

- Relates the foreign language to the target culture.

- Explains tasks clearly; a teacher who is varied with regard to materials.

- Is flexibie with regard to objectives.

- Builds up on pupil error; a teacher who provides a variety of language activities.

- Involves the whole group.

- Is skilled in handling equipment.

- Promotes use of the foreign language by pupils.

Bailey (1985) presents the results of classroom research on «the good language teacher». Some of the characteristics of outstanding teachers' lessons involved:

1. More use of the foreign language by the teacher and the students combined.

2. More teacher talk in the foreign language.

3. More student talk in the foreign language.

4. Less student talk which is off the task.

5. More indirect behaviors in the lesson.

6. More indirect behaviors in the foreign language.

7. More nonverbal indirect behaviors.

8. More use of praise and joking.

9. More use of personalized questions.

10. More nonverbal information giving (i.e., gesturing to convey meaning).

Miller (1987:49) comments precisely on the ten characteristics of a good teacher. She wants a teacher who has a contagious enthusiasm for his teaching (one who, as Richard Via (1985:12) says, «loves his students and his work»). She wants a teacher who is creative: There are myriad of techniques which the creative teacher can employ. She wants a teacher who can add pace and humor to the class: As Krashen would say, the affective filters of the students were low, facilitating acquisition. She wants a teacher who challenges me: Speaking in the target language to the learner prepares and challenges him to speak in that language. Miller (1987:49) wants a teacher who is encouraging and patient, and who will not give up on me. She wants a teacher who will take an in- 
terest in me as a person- one who will try to discover discussion topics that interest me. The author wants a teacher who knows grammar well and who can explain something on the sport if necessary. She wants a teacher who will take a minute or two to answer a question after class; a teacher who wil treat me as a person, on an equal basis with all the members of the class, regardless of sex, marital status, race, or my future need for the language. Finally, she wants a teacher who will leave his emotional baggage outside the classroom.

In conclusion, she states the qualities of a good teacher can be separated in four areas: 1) affective characteristics: enthusiam, encouragement, humor, interest in the student, availability, mental health; 2) skills: creativity, challange; 3) classroom management: pace, pairness; 4) academic knowledge: grammar.

Finocchiaro (1988) reflects on how a teacher should grow or what is required for teacher development:

1. Planning lessons several days in advance.

2. Keeping a simple brief checklist of the material presented.

3. Writing the homework assigment for the next lesson.

4. Never giving homework over a holiday.

5. Always greetting the class chierfully.

6. Spending a few minutes after the greeting, indicating your awareness of individual students.

7. Giving a 30 -second written quizz every day.

8. establishing a routine for distributing and collecting papers.

9. Sending an able student to the chalkboard to ask questions.

10. Returning the test papers to the students.

11. Most essential: leaving your lesson plan in your desk or in the principal's office when you know you will be absent.

She goes on to specify the characteristics of superior teachers. They:

- Recognize and make provision for the fact that all the students learn at different rates and in different ways.

- Know that the learners must feel loved, respected, and secure.

- Are teachers who keep the motivation of students at a high level.

- Reassure and encourage students when they reach a plateau in learning.

- Recognize that the correction of student errors is a matter requiring sensitivity and, above all, common sense.

- Organize each learning experience carefully.

- Plan in advance the communication situations and the meaningfulcontexts through which the communicative purposes of all listening and reading material will be made clear. 
- Provide in each lesson not only for pronunciation practice leading to necessary habit formation, but also to real-world use of the language.

- Use the students' native language sparingly in the classroom.

- Have learned to plan language activities in pairs or small groups that duplicate or simulate those needed and used for in actual communication. Those teachers have learned to supplement the basic text where necessary.

- Have become skillful in preparing scripts for tapes, in voicing them, and in integrating laboratory, video, or computer practice with classroom activity.

- Are aware of the fact that there are no passive language skills.

- Plan reading lessons that will not only extend the pupols' knowledge of the language but will also foster discussion and thought.

- Incorporate guided writing activities in their lesson plans, which will lead gradually to more creative, «freer» student composition.

- Provide students with cross-cultural insights.

- Make sure that students retain their sense of individual dignity and ethnic pride while learning to appreciate aspects of English.

- Learn to select and use only those audiovisual aids that will enable the students to comprehend a particular communicative expression, grammatical structure, specific notion, or cultural fact more efficiently and effectively.

- Create an opportunity for learning from individual experiences the students may have had. They utilize the strengths of older students by having them help in the numerous tasks in the classroom.

- Use the same piece of material for multiple purposes. Where feasible, the teacher plans out-of-school visits for students so that they may meet with people of the community. ( $S$ )he prepares and gives frequent tests that will help gauge the achievement and proficiency of $s t u-$ dents, diagnose individual learning problems, and judge the effectiveness of his or her own teaching procedures. In sum, the teacher is educator, counselor, guide, and friend, a model that students respect and want to emulate.

Kral (1988:7) presents some guidelines for the foreign language teacher:

1. Draw upon the students' background and intelligence.

2. Create a secure learning environment.

3. Be selective in presenting new language materials.

4. Allow time for reflection. 
5. Allow repetition of activities.

6. Recycle information

7. Promote meaningful language exchange through self-expression.

8. Identify language errors at an appropiate time.

According to Champeau de López (1989) there are some main areas where the approach to language teaching has changed: 1) The emphasis on the individual learner: the focus has shifted from the teacher to the learner. 2) Eclecticism: The recent tendency is towards eclecticism, selecting different materials and techniques from various sources taking into acxcount that every student has his/her own personality traits. 3) Communication in a social context: Now the emphasis is on what a language does (function) as well as on what it is (structure). Teachers are concerned about communicative competence. 4) Psychological factors: Nowadays teachers must be aware of the 'schemata' or the knowledge his/her students possess: The background knowledge of the content area under study and the background knoeledge regarding the language itself. 5) The cognitive learning styles of his/her students: There are different learning styles and the teacher must find the best way of teaching the different students in class. 6) Affective factors should be considered: Psychology has stressed the importance of self-esteem in the process of language learning. 7) Attention should be paid to the student's needs: The teacher should know what are the goals of his/her students for studing a second/foreign language. 8) The social factors are of vital importance: the teacher must know the social environment of each student.

Altaha and El-Hibir (1990) list the even qualities of a successful foreignlanguage teacher: 1) one who is well trained, 2) one who gives equal opportunities to each student, 3) one who mantains a friendly atmosphere in his/her classes, 4) one who makes sure his/her students are not afraid of making mistakes while speaking or writing, 5) one who is firm, 6) one who loves his/her profession and does not go into teaching by accident, 7) one who is aware of the individual differences among his/her students.

Prodromou (1991) wrote a very precise and clear article. In it he reported the results of a survey designed to discover students' views of good and bad language teaching. Over 40 students (intermediate to advanced level) were involved in the survey. Some of the characteristics of the good language teacher were: friendly, explained things, gave good notes, knew how to treat someone who sits at a desk for six hours, let the students do it by themselves- group work, etc.

They also listed some of the traits which characterized the bad language teacher: very strict, didn't let us speak, gave us a text to learn and check, gave marks all the time, she was fixed on a chair, etc. 
On Prodromou's opinion the ways of improving one's knowledge of ELT and increase one's confidence as a teacher include:

1. Subscribing to ELT magazines and journals.

2. Joining professional organizations and attending their conferences.

3. Forming local teachers' groups and holding regular meetings to discuss common problems.

4. Inviting fellow teachers/teacher trainers and guest speakers to contribute lectures and workshops.

5. Publishing an ELT newsletter on a local or national scale.

6. Arranging ELT book exibitions with the help of ELT publishers and organizations.

7. Joining a special-interest group.

8. Reading teachers' handbooks published by most ELT publishers.

In his article Prodromou includes a list of 20 questions which can serve to observe the role of the teacher. They include such questions as: 1) Was the lesson mostly testing or mostly teaching?, 2) Did comprehension questions check comprehension?, 3) Did the teacher give reasonably accurate answers to students questions?, 4) Was the teacher's reaction to student errors encouraging or discouraging?, etc.

Ancker's article (1992) starts by coinciding with Finocchiaro (op. cit.) in considering teacher development as an ongoing process. She agrees with the fact that «teachers are made, not born». The author asked his MA TEFL students what advice they would give to teacher trainees about foreign-language teaching. Their suggestions could be grouped in three categories: 1) classroom management (use the target language in class, speak at the students' level, state the lesson's objectives at the beginning of each class, give clear instructions), 2) relationship with students ( motivate students in the first few minutes of each class, give positive feedback, avoid immediate error correction), 3) personal traits (be organized, be punctual, be cheerful and energetic in class).

In his book Scrivener (1994:15) lists some pieces of advice for language teachers. He tells us to remember the characteristics suggested by Carl Rogers for creating an effective learning environment: $\mathrm{Be}$ as honestly yourself as you can be. Respect the learners. Work on seeing things from your students' perspective as well as your own. Encourage a friendly, relaxed learning environment. It there is a trusting, positive, supportive rapport amongst the learners and between learners and teacher, then there is a much better chance of useful interaction happening. Ask questions rather than giving explanations. When you want students to discuss something, ask 'open' questions (eg. where, what, who, 
why, how, when questions that require a longer answer) rather than closed questions (eg. questions that require nothing more than yes or no). Allow time for students to listen, think, process their answer and speak. Really listen to what they say. Let what they say really affect what you do next. Work on listening to the person, and the meaning, as well as to the language and the mistakes. Allow thinking time without talking during it. Allow silence. Increase opportunities for STT (Student Talking Time). Use gestures to replace unnecessary teacher talk. Allow students to finish their own sentences. Make use of pairs and small groups to maximize opportunities for students to speak. If possible, arrange seating so that students can all see each other and talk to each other (i.e. circles, squares and horseshoes rather than parallel rows). Remember that the teacher doesn't always need to be at the front of the class. Try out seating arrangements that allow the whole class to be the focus (e.g. teacher takes one seat in the circle). Encourage interaction between students rather than only between student and teacher and teacher and student. Get students to ask questions, give explanations, etc. to each other rather than always to you. Use gestures and facial expressions to encourage them to speak and listen to each other. Encourage cooperation rather than competition. In many activities (probably not in a test or exam) you may want to encourage students to copy ideas from others, or "cheat'. Allow students to become more responsible for their own progress. Put them in situations where they need to make decisions for themselves.

If a student is speaking too quietly for you to hear, walk further away, rather than closer to them! (This sounds illogical- but if you can't hear them, then it's likely that the other students cannot either. Encourage the quiet speaker to speak louder so that the others can hear.)

Al-Arishi (1994) stresses the importance of designing activities that permit the use of introspection before, during, and after interaction. He lists the main ones:

1. Complement brainstorming activities with brain-besieging activities.

2. Develop activities that encourage hypothesis-formulating.

3. Make use of process-oriented activities.

4. Plan, but do not dictate, the synthesizing of activities.

Brosh (1996) carried out an investigation on the characteristics of good language teachers. The research included two groups: the first one was made up of 200 foreign language teachers of English, French, Arabic or Hebrew. None of them was a native speaker of the language. The second group included 406 ninth-grade high school students from ten different schools in Tel Aviv. The data were collected by a questionnaire (it included a list of 20 ELT 
characteristics) and interviews. The desirable characteristics of the effective language teacher are:

1. Knowledge and command of the target language.

2. Ability to organize, explain, and clarify, as well as to arouse and sustain interest and motivation among students.

3. Fairness to students by showing neither favoritism nor prejudice.

4. Availability to students.

The article finishes stressing the importance that the teacher's personality can have on determining his or her success or failure.

Last but not least, we have to say that the Internet is another source of information on the topic of 'good teachers'. Under the heading of 'master teachers' there are some Web pages dealing with the characteristics of the good language teacher. We can mention the URL http://www.4w.com/hoe, which contains the article $« 40$ helpful hints and tips, for making your ESL teaching easier and more fun». This article appeared in the July/August 1994 issue of the on-line magazine Hands-on English. Another good site is the one called «Beste Teacher Description» which contains a list of characteristics and techniques that make a successful teacher: http://humanities.byu.edu/elc/Teacher/BestTeacher.

It is my hope that those teachers who have been kind enough to read my article will benefit from the ideas contained in it. My aim was to improve myself as a foreign language teacher and perhaps, help other colleages by reflecting on the topic.

I would like to conclude with these words:

The good teacher tells, the better teacher explains, the superior teacher demonstrates, the great teacher inspires.

\section{REFERENCES}

AL-ArISHI, A.Y. (1994): «Practical ways to Promote Reflection in the ESL/EFL Classroom». English Teaching Forum, 32/2:2-5.

AlLEN, B. (1987): «Identifying the Behaviours of the Master Teacher». Spectrum, 5/2:42-47.

AlTAHA, F.M. and B.I. EL-HibIR (1990): «The Characteristics of EFL Teachers from a New Perspective». English Teaching Forum, 28/1:42-44.

ANKER, W. (1992): «Advice on Language Teaching from Language Teachers». English

Teaching Forum, 30/4:47-48. 
AYDELOTT, J. (1990): «What makes a good teacher? Review of research on effective teaching». Paper presented at Bilkent University School of English Language, Ankara, Turkey.

BAILEY, K.M. 1985: «Classroom-centred Research on Language Teaching and Learning», en CelCe-MurCiA, M. (ed.) (1985): Beyond Basics. Issues and Research in TESOL. Rowley, Mass.: Newbury House.

Brosh, H. (1996): «Perceived Characteristics of the Effective Language Teacher». Foreign Language Annals, 29/2:125-138.

ÇıFTÇı, D. (1983): «Some Hints for New (and Experienced) Teachers». English Teaching Forum, 21/3:42-43.

Champeau DE LOPEZ, C.L. (1989): «The Role of the Teacher in Today's Language Classroom». English Teaching Forum, 27/3:2-5.

ChAUdRON, C. (1988): Second Language Classroom: Research on Teaching and Learning. Cambridge: Cambridge University Press.

Dulay, H, M. BurT and S. KRAShen (1982): Language Two. Oxford: Oxford University Press.

FinocChiaro, M. y M. Bonomo (1973): The Foreign Language Learner. New York: Regents Publishing Co.

FinOCCHIARO, M. (1976): «M-o-t-i-v-a-t-i-o-n in Language Learning». English Teaching Forum, 14/3:4-8.

Finocchiaro, M. (1988): «Teacher Development: A Continuing Process». English Teaching Forum, 26/3:2-5.

GIRARD, D. 1986: «The Eclectic Way». English Teaching Forum, 24/3:11-14.

Hands-on-English, (1997): «40 Helpful Hints and Tips for Making your ESL Teaching Easier and More Fun». Hands-on-English, electronic document at http: //www.4w.com/hoe/

KOLF, D. (1990): «The EFL Teacher as Artist». English Teaching Forum, 28/1:4041.

KRAL, T.J. (1988): «Life-Saving Techniques for the Foreign-Language Learner Lost at Sea». English Teaching Forum, 26/3:6-14.

Lennon, P. (1988): «The Linguist and The Language Teacher: Love at First Sight or the End of the Honeymoon?» English Teaching Forum, 26/4:2-5.

Miller, P. (1987): «Ten Characteristics of a Good Teacher». English Teaching Forum, 25/1:40-41.

Penner, J.G. (1992): Why Many College Teachers Cannot Lecture. Illinois: Charles C. Thomas.

POLITZER, R.L. and L. WeIss (1971): The Successful Foreign Language Teacher. Philadelphia, PA: The Center for Curriculum Development.

PratoR, C. (1976): «In Search of a Method». English Teaching Forum, 14/1:2-8.

Prodromou, L. (1991): «The Good Language Teacher». English Teaching Forum, 29/2: 2-7. 
RoBINETT, B.W. (1977): «Characteristics of an Effective Second Language Teacher» in M. Burt, H. Dulay and M. Finocchiaro (eds.) (1977): Viewpoints on English as s Second Language. New York: Regents Publishing Co.

SANDERSON, D. (1983): Modern Language Teachers in Action: A Report on Classroom Practice. York: Language Materials Development Unit of the University of York.

SCRIVEner, J. (1994): Learning Teaching. Oxford: Oxford University Press.

VILLA, A. (1985): Un modelo de profesor ideal. Madrid: Ministerio de Educación y Ciencia. 